\title{
Accountable Communities for Health: Moving From Providing Accountable Care to Creating Health
}

\author{
Renuka Tipirneni, $M D, M S c^{1-3}$ \\ Katherine Diaz Vickery, MD, \\ $M \mathrm{Mc}^{4,5}$
}

Edward P. Eblinger, MD, MSPH

'Robert Wood Johnson Foundation Clinical Scholars Program, University of Michigan, Ann Arbor, Michigan

${ }^{2}$ Department of Internal Medicine, University of Michigan, Ann Arbor, Michigan

${ }^{3}$ Institute for Healthcare Policy \& Innovation, University of Michigan, Ann Arbor, Michigan

${ }^{4}$ Department of Medicine, Hennepin County Medical Center, Minneapolis, Minnesota

${ }^{5}$ Department of Medicine, University of Minnesota Medical School, Minneapolis, Minnesota

${ }^{6}$ Minnesota Department of Health, St. Paul, Minnesota

Conflicts of interest: authors report none.

\section{CORRESPONDING AUTHOR}

Renuka Tipirneni, MD, MSc

Robert Wood Johnson Foundation Clinical Scholars Program

University of Michigan

2800 Plymouth Rd, Bldg 10, Rm G016

Ann Arbor, MI 48109-2800

rtipirne@med.umich.edu

\begin{abstract}
Lessons from community-oriented primary care in the United States can offer insights into how we could improve population health by integrating the public health, social service, and health care sectors to form accountable communities for health (ACHs). Unlike traditional accountable care organizations (ACOs) that address population health from a health care perspective, ACHs address health from a community perspective and consider the total investment in health across all sectors. The approach embeds the ACO in a community context where multiple stakeholders come together to share responsibility for tackling multiple determinants of health. ACOs using the ACH model provide a roadmap for embedding health care in communities in a way that uniquely addresses local social determinants of health.
\end{abstract}

Ann Fam Med 2015;13:367-369. doi: 10.1370/afm.1813

\section{INTRODUCTION}

I $\mathrm{n}$ the era of the Patient Protection and Affordable Care Act, accountable care organizations (ACOs) are increasingly charged not only with improving quality of care and reducing health care costs, but also with addressing the third aspect of the Triple Aim-improving the health of the population. Yet population health improvement has been poorly defined and difficult to implement through a health care system focused on individual patients with individual diagnoses. Lessons from past endeavors to build community-oriented primary care (COPC) in the United States can offer insights into how we could improve population health by integrating the public health and health care sectors within a community context to form accountable communities for health (ACHs).

\section{Historical Legacy}

Jack Geiger, originator of community health centers in the United States, brought COPC's distinctive integration of public health and medicine to this country after working with founders Sidney and Emily Kark in South Africa. ${ }^{1,2}$ COPC emerged from efforts to improve health through engagement of community members in identifying health needs and addressing social determinants of health, such as housing, sanitation, and food. ${ }^{3,4}$ This early model enabled primary health care to respond more readily to local populations' needs and laid the groundwork for later communityengaged reforms.

\section{Current Opportunity}

The current momentum for health reform since the passage of the Patient Protection and Affordable Care Act provides us with an opportunity to rediscover the broad health benefits of the COPC approach. ACOs provide a much-needed vehicle ${ }^{5}$ to harness COPC principles to reconsider what creates health, to redesign local health systems, and to rebalance our investment in the health of our communities. Conventionally ACOs have been defined as groups of health care providers who coordinate 
care delivery for patients so that higher quality can be achieved at lower cost. ${ }^{6}$ Although using such networks to improve population health seems like a natural next step, efforts at community linkage have been rare. Currently, of the 606 ACOs operating in the United States, fewer than 50 are sponsored by communitybased organizations. Most ACOs are instead sponsored by physician groups, hospitals, and insurers. ${ }^{7,8}$ Furthermore, this number likely overestimates true community involvement in ACOs, as the count includes commercial practice management companies.

\section{ACCOUNTABLE COMMUNITIES FOR HEALTH}

To achieve population health improvement, health care should be aligned with other sectors, ${ }^{9}$ such as education, business, and community organizations, to form what are being called ACHs (also called accountable care communities or accountable health communities). ${ }^{10,11}$ Unlike traditional ACOs, which address population health from a health care perspective, $\mathrm{ACH}$ address health from a community perspective. The approach integrates health care with public health and social services, and embeds the organization in a community where multiple stakeholders come together as a powerful coalition that shares responsibility for tackling multiple determinants of health. ${ }^{12}$ This coalition considers not just the total cost of health care, it considers the total investment in health across all sectors. In this way, ACHs uniquely organize and engage the community-wide coalition necessary to address broad social determinants of health within an ACO context to meaningfully impact health.

\section{Case Studies}

Federal agencies such as the Centers for Medicare \& Medicaid Services and the Centers for Disease Control and Prevention have spurred creation of many such community $\mathrm{ACO} / \mathrm{ACH}$ models by funding demonstration projects. Although there are many similar efforts across the country, we discuss 2 exemplary $\mathrm{ACH}$ models here.

First, a notable $\mathrm{ACH}$ that has formed within the context of a health plan is Hennepin Health, a Medicaid demonstration project serving more than 10,500 enrollees in Minneapolis, Minnesota. Operating under a capitated finance model administered by a countyoperated insurance plan since January 2012, Hennepin Health partners social service and public health leaders with local safety net health care providers through a risk-sharing arrangement that aligns their financial incentives in powerful ways. ${ }^{13,14}$ In addition to sharing financial risk, the group integrates social service data with enrollee claims utilization data and electronic health records through a unique data warehouse that is shared across the 4 member organizations and used to produce ad-hoc analyses, as well as a scorecard of operational metrics that is updated monthly. Recognizing that social and behavioral needs are often key drivers of poor health, Hennepin Health also links patients with services not traditionally financed through the health care sector, such as vocational training and housing support. For example, with grant support from Minnesota's State Innovation Model (SIM) program, Hennepin Health has developed specific initiatives to target their high-risk enrollees who are clients of the county's jail or Adult Corrections Facility. Estimated to serve 110 enrollees over 2 years, the project invests heavily in housing placements, employment supports, and community health workers to reduce homelessness, unemployment, and the recidivism that often results ( $R$. Owen, personal communication, April 7, 2015). The program hypothesis is that ensuring housing and other supports during high-risk enrollees' transition back to the community will achieve health care savings. Data from the enrolled cohort in Hennepin Health from 2012 to 2013 demonstrated decreased emergency department utilization (9.1\%) and inpatient hospital admissions $(3.0 \%)$, as well as increased rates of optimal care delivery for enrollees with diabetes, vascular disease, and asthma. ${ }^{13}$ This program has provided needed care for less than the per-member-per-month rates, and used a portion of the cost efficiencies toward $\$ 2.4$ million in reinvestment initiatives. Although these early results are encouraging, the observational nature of the data limits interpretation of causal impact, and long-term evaluation of downstream health and social outcomes, as well as utilization and costs, is currently under way.

Second, a noteworthy example of $\mathrm{ACH}$ defined by a geographic community is the Akron Biolnnovation Institute's Accountable Care Community initiative, formed in 2011. The group consists of more than 70 stakeholders across Summit County, Ohio, including the major local hospitals, health care providers, universities, businesses, faith-based organizations, housing groups, transportation authorities, economic developers, and planners. ${ }^{15}$ Through collaboration across payers and sectors, they have achieved impressive gains. For example, with their diabetes initiative, they worked to address a problem with a high local burden $(11 \%)$ of disease in their community. ${ }^{15}$ Participants in the program-which included increasing access to fruits and vegetables, and changes in the environment to increase healthy behaviors-were able to achieve significant weight loss and reductions in hemoglobin $\mathrm{A}_{1 \mathrm{C}}$ levels. Moreover, monthly costs for diabetic members were reduced by $10 \%$ to $25 \% .{ }^{15}$ The 
Akron group has targeted interventions to address local health needs and capitalized on its community assets. Participating health care providers and community groups share in the savings and reinvest the funds toward future initiatives.

Similar ACH frameworks are rolling out in regional networks across states within Medicaid ACOs in Oregon and Colorado. Likewise, $\mathrm{ACH}$ s are being planned or implemented across payers in states such as Minnesota through their SIM initiative. Such statewide models have the potential to change considerably the scope of how ACOs can be used to affect health.

\section{CONCLUSION}

Improving population health will require a redesign of our health care system so that it integrates medical care, public health, and social services. ACOs using the $\mathrm{ACH}$ model provide a roadmap for embedding health care in communities in a way that uniquely addresses local social determinants of health. The Affordable Care Act paves the way for renewed commitment to population health, but it is up to us to walk down that road by embracing accountable communities for health on a broad scale.

To read or post commentaries in response to this article, see it online at http://www.annfammed.org/content/13/4/367.

Key words: community-oriented primary care; health reform; population health; accountable care organizations

Submitted November 24, 2014; submitted, revised, April 21, 2015; accepted April 30, 2015

Funding support: Dr Tipirneni receives salary support from the Robert Wood Johnson Foundation Clinical Scholars Program.

Acknowledgments: Ana V. Diez Roux, MD, PhD, MPH (Drexel University School of Public Health); Lauren S. Hughes, MD, MPH (University of Michigan Robert Wood Johnson Foundation Clinical Scholars Program); and Ross Owen, MPA (Hennepin County) provided thoughtful discussion and feedback on earlier drafts of this article.

\section{References}

1. Longlett SK, Kruse JE, Wesley RM. Community-oriented primary care: historical perspective. J Am Boardf Fam Pract. 2001;14(1):54-63.

2. Kark SL, Kark E. An alternative strategy in community health care: community-oriented primary health care. Isr J Med Sci. 1983;19(8): 707-713.

3. Mullan F, Epstein L. Community-oriented primary care: new relevance in a changing world. Am J Public Health. 2002;92(11):1748-1755.

4. Nutting PA. Community-Oriented Primary Care: From Principle to Practice. Washington, DC: US Dept. of Health and Human Services, Public Health Service, Health Resources and Services Administration, Office of Primary Care Studies; 1987.

5. Shortell SM. Bridging the divide between health and health care. JAMA. 2013;309(11):1121-1122.

6. Center for Medicare \& Medicaid Services. Accountable Care Organizations (ACO). 2015. https://www.cms.gov/Medicare/Medicare-Feefor-Service-Payment/ACO/index.html?redirect=/aco. Accessed Apr 8, 2015.

7. Muhlestein DB. Continued growth of public and private accountable care organizations. Vol 2013. Health Affairs Blog. http:// healthaffairs.org/blog/2013/02/19/continued-growth-of-public-andprivate-accountable-care-organizations. Accessed Feb 23, 2015.

8. Muhlestein DB. Accountable care growth in 2014: a look ahead. Vol 2014. Health Affairs Blog. http://healthaffairs.org/blog/2014/01/29/ accountable-care-growth-in-2014-a-look-ahead. Accessed Feb 23, 2015.

9. Institute of Medicine. For the public's health. the role of measurement in action and accountability. 2010. http://www.iom.edu/ Reports/2010/For-the-Publics-Health-The-Role-of-Measurement-inAction-and-Accountability.aspx. Accessed Apr 9, 2015.

10. Hacker K, Walker DK. Achieving population health in accountable care organizations. Am J Public Health. 2013;103(7):1163-1167.

11. Magnan S, Fisher E, Kindig D, et al. Achieving accountability for health and health care. Minn Med. 2012;95(11):37-39.

12. Somers S, McGinnis, T. Broadening the ACA story: a totally accountable care organization. Health Affairs Blog [published online Jan 23, 2014]. http://healthaffairs.org/blog/2014/01/23/broadeningthe-aca-story-a-totally-accountable-care-organization/?utm_source $=$ Health +Affairs + Blog $\% 3 \mathrm{~A}+$ Introducing +Totally +Accountable + Care + Organizations + Eutm_campaign $=$ Health + Affairs + Blog + eAlertEutm_medium=email. Accessed Apr 9, 2014.

13. Sandberg SF, Erikson C, Owen R, et al. Hennepin Health: a safetynet accountable care organization for the expanded Medicaid population. Health Aff (Millwood). 2014;33(11):1975-1984.

14. Blewett LA, Owen RA. Accountable care for the poor and underserved: Minnesota's Hennepin Health model. Am J Public Health. 2015;105(4):622-624.

15. Austen Biolnnovation Institute In Akron. Healthier by design: creating accountable care communities. http://www.faegrebdc.com/ webfiles/accwhitepaper12012v5final.pdf. Accessed Apr 8, 2015. 